\title{
Persistent Arthralgia Associated with Chikungunya Virus Outbreak, US Virgin Islands, December 2014-February 2016
}

\section{Leora R. Feldstein, Ali Rowhani-Rahbar, J. Erin Staples, Marcia R. Weaver, M. Elizabeth Halloran, Esther M. Ellis}

After the 2014-2015 outbreak of chikungunya virus in the US Virgin Islands, we compared the prevalence of persistent arthralgia among case-patients and controls. Prevalence was higher in case-patients than controls 6 and 12 months after disease onset. Continued vaccine research to prevent acute illness and long-term sequelae is essential.

\begin{abstract}
A utochthonous transmission of chikungunya virus (CHIKV) was first reported in the Americas in December 2013 on the island of Saint Martin, and by early 2016, the virus had spread to 45 countries in the Caribbean and Central, South, and North America $(1,2)$. Acute symptoms of CHIKV infection often resolve within 7-10 days (3). However, $7 \%-79 \%$ of case-patients from previous outbreaks have reported persistent arthralgia for months after infection (4-8). Persistent arthralgia associated with CHIKV illness has been assessed in persons in Southeast Asia, South America, and Europe but not in the Caribbean $(4,9)$.

The US Virgin Islands (USVI), one of many regions in the Caribbean affected by the CHIKV epidemic, identified its first locally acquired case in June 2014 (10). USVI subsequently reported nearly 2,000 suspected CHIKV cases before the last laboratory-confirmed case was reported in February 2015 (11). To determine the prevalence of CHIKV-associated persistent arthralgia in USVI, we compared the prevalence of persistent arthralgia among CHIKV case-patients and nonsymptomatic controls during December 2014-February 2016.
\end{abstract}

Author affiliations: Fred Hutchinson Cancer Research Center, Seattle, Washington, USA (L.R. Feldstein, M.E. Halloran); University of Washington, Seattle (A. Rowhani-Rahbar, M.R. Weaver, M.E. Halloran); Centers for Disease Control and Prevention, Fort Collins, Colorado, USA (J.E. Staples); US Virgin Islands Department of Health, Saint Croix, US Virgin Islands (E.M. Ellis)

DOI: http://dx.doi.org/10.3201/eid2304.161562

\section{The Study}

A confirmed case-patient was defined as a USVI resident of any age with acute onset of fever $\left(\geq 38^{\circ} \mathrm{C}\right)$ and severe arthralgia or arthritis not explained by another medical condition plus 1 of the following: 1) CHIKV RNA in blood, as determined using reverse transcription PCR, or 2) CHIKV-specific IgM antibodies in serum, as determined using ELISA in conjunction with either CHIKV-specific neutralizing antibodies using plaque reduction neutralization test with a $90 \%$ cutoff or CHIKV-specific IgG using ELISA (10). Confirmed case-patients captured by the USVI Department of Health surveillance system were invited via telephone to participate in a follow-up investigation at 6 and 12 months after acute illness; a total of 165 case-patients were recruited. Verbal informed consent was obtained at the start of each interview.

At the 12-month follow-up, we concurrently enrolled a nonsymptomatic control group. Members of the control group were recruited from the emergency department waiting room of a hospital or from a health clinic in USVI; the group comprised 167 USVI residents of any age. Persons were not eligible for the control group if they reported symptoms consistent with CHIKV disease (i.e., concurrent fever and acute joint pain) or responded "yes" to being tested for CHIKV and test results were positive. All controls were offered free CHIKV IgG testing and were excluded from analysis if positive (online Technical Appendix Table 1, https://wwwnc.cdc.gov/EID/article/23/4/16-1562Techapp1.pdf).

At 6 and 12 months, we interviewed case-patients about presence, frequency, and anatomic location of arthralgia after acute CHIKV infection. We defined persistent arthralgia as joint pain occurring at least once per week within 1 month before the interview. We asked casepatients whether they had a history of arthritis (defined as doctor-diagnosed arthritis before CHIKV illness). At the 12-month interview, we asked case-patients whether they had difficulty performing everyday activities (i.e., walking, climbing stairs, lifting heavy objects, getting in and out of cars, opening jars). We interviewed the control group only once, using the same 12-month questionnaire that we used for case-patients. The University of the Virgin Islands and the University of Washington ethics committees approved this study. 
Table 1. Prevalence and prevalence ratios of persistent arthralgia and impaired physical functionality among residents in a study of persistent arthralgia after a chikungunya virus outbreak, US Virgin Islands, December 2014-February 2016*

\begin{tabular}{|c|c|c|c|c|}
\hline Variable & Prevalence difference $(95 \% \mathrm{Cl})$ & $p$ value & Prevalence ratio $(95 \% \mathrm{Cl})$ & $p$ value \\
\hline \multicolumn{5}{|l|}{ Persistent arthralgia } \\
\hline $\begin{array}{l}6 \text { month analysis* } \\
12 \text { month analysis* }\end{array}$ & $\begin{array}{l}0.32(0.24-0.40) \\
0.19(0.11-0.28)\end{array}$ & $\begin{array}{c}<0.001 \\
0.001\end{array}$ & $\begin{array}{l}2.90(1.90-4.43) \\
2.51(1.71-3.69)\end{array}$ & $\begin{array}{l}<0.001 \\
<0.001\end{array}$ \\
\hline \multicolumn{5}{|c|}{ Difficulty performing daily activities } \\
\hline Walking & $0.11(0.03-0.18)$ & 0.007 & $1.77(1.06-2.95)$ & 0.028 \\
\hline Climbing stairs & $0.12(0.05-0.19)$ & 0.001 & $1.81(1.15-2.86)$ & 0.011 \\
\hline Lifting heavy objects & $0.04(-0.02-0.11)$ & 0.209 & $1.68(0.96-2.97)$ & 0.072 \\
\hline Getting in and out of cars & $0.09(0.03-0.14)$ & 0.001 & $2.65(1.32-5.32)$ & 0.006 \\
\hline Opening jars & $0.15(0.07-0.23)$ & $<0.001$ & $2.24(1.28-3.91)$ & 0.005 \\
\hline
\end{tabular}

At each time point, we ran 2 independent regression models. We constructed generalized linear models, using the binomial family with robust variance estimators, to estimate prevalence differences and prevalence ratios. We included age grouping $(\leq 35,36-55$, and $>55$ years), sex, and self-reported history of arthritis in the models. We used 2-sample $t$-tests with unequal variances to determine differences in arthralgia prevalence by affected joint sites. We used Stata 14.0 (StataCorp LLC, College Station, TX, USA) for the analysis.

Six months after disease onset, the difference in persistent arthralgia prevalence between case-patients and controls was $32 \%$ (95\% CI $24 \%-40 \%$ ), after adjusting for age, sex, and self-reported history of arthritis; 12 months after onset, the difference was $19 \%$ (95\% CI 11\%-28\%) (Table 1). At 6 months, case-patients reported higher prevalence of foot-specific joint pain $(28 \%, 95 \%$ CI $11 \%-44 \%)$, and at 12 months, controls reported higher prevalence of kneespecific pain $(29 \%, 95 \%$ CI $8 \%-50 \%)$ (Figure 1). At 12 months, we found no statistically significant differences by joint site between case-patients and controls (Figure 2).

After we adjusted for age, sex, and self-reported history of arthritis, case-patients were 1.77 (95\% CI 1.06-2.95) times more likely than controls to have difficulty walking and 1.81 (95\% CI 1.15-2.86) times more likely to have difficulty climbing stairs (Table 1). Case-patients were also

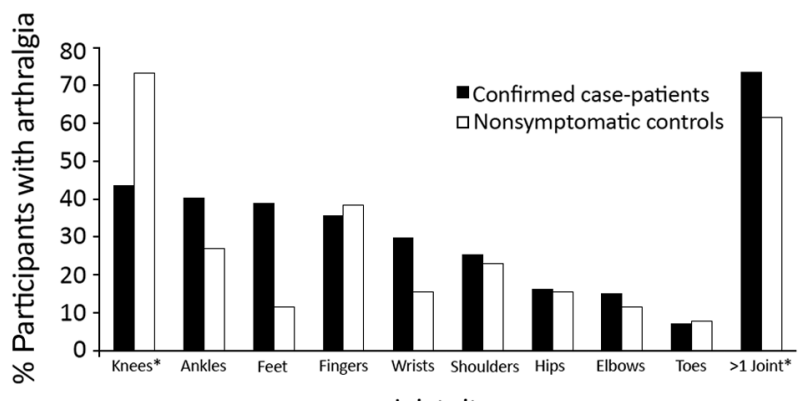

Joint site

Figure 1. Arthralgia reported by joint site among confirmed chikungunya virus case-patients 6 months after illness onset and by nonsymptomatic controls enrolled at the time of the 12-month follow-up for case-patients, US Virgin Islands, December 2014February 2016. *Statistically significant differences $(p<0.01)$ between case-patients and controls.
2.65 (95\% CI 1.32-5.32) times more likely to have difficulty getting in and out of cars and 2.24 (95\% CI 1.28-3.91) times more likely to have difficulty opening jars.

\section{Conclusions}

Although acute symptoms of CHIKV infection are well-documented (12), information on the prevalence of long-term sequelae remains limited to observational studies, many of which lack comparator groups (4). From our year-long study of 165 case-patients and 167 controls, we found an almost 3 -fold increased risk for persistent arthralgia in CHIKV casepatients at 6 and 12 months after illness onset. At 12 months, case-patients were significantly $(\mathrm{p}<0.01)$ more likely than controls to report difficulty performing daily activities. Our unadjusted persistent arthralgia estimates at $6(44 \%)$ and 12 (33\%) months (Table 2) fall within the pooled estimate from a metaanalysis ( $40 \%, 95 \%$ CI $31 \%-49 \%)$ (4).

Consistent with findings in previous studies, casepatients in our study reported a higher prevalence of footspecific joint pain, $(6,8,13,14)$. Furthermore, a higher proportion of case-patients reported the presence of persistent arthralgia and of more severe arthralgia in the morning; this finding is consistent with those from previous studies reporting a high prevalence of morning stiffness among case-patients $(6,8)$.

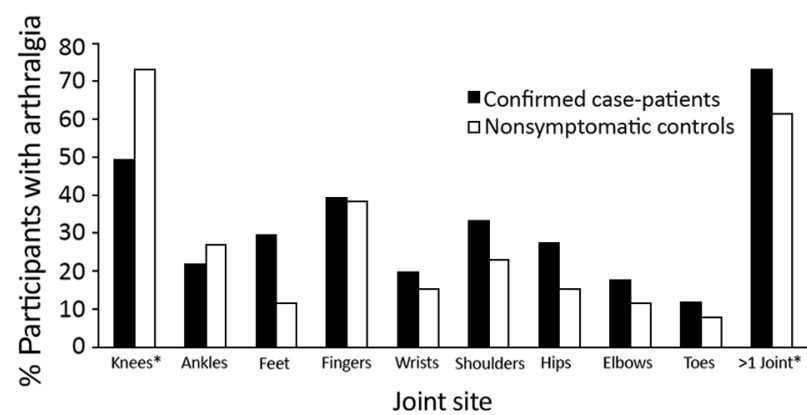

Figure 2. Arthralgia reported by joint site among confirmed chikungunya virus case-patients 12 months after illness onset and by nonsymptomatic controls enrolled at the time of the 12-month follow-up for case-patients, US Virgin Islands, December 2014February 2016. No statistically significant differences were found between case-patients and controls. 
Table 2. Demographic and physical characteristics among residents in a study of persistent arthralgia after a chikungunya virus outbreak, US Virgin Islands, December 2014-February 2016*

\begin{tabular}{|c|c|c|c|}
\hline \multirow[b]{2}{*}{ Variable } & \multicolumn{2}{|c|}{ No. $(\%)$ chikungunya virus case-patients } & \multirow{2}{*}{$\begin{array}{l}\text { No. }(\%) \text { nonsymptomatic } \\
\text { controls at } 12 \text {-month case- } \\
\text { patient follow-up, } \mathrm{N}=167^{*}\end{array}$} \\
\hline & $\begin{array}{c}6 \text { months after symptom } \\
\text { onset, } \mathrm{N}=165\end{array}$ & $\begin{array}{c}12 \text { months after symptom } \\
\text { onset, } \mathrm{N}=128\end{array}$ & \\
\hline Median age (range), y & $52(1-96)$ & $52(1-92)$ & $35(2-78)$ \\
\hline \multicolumn{4}{|l|}{ Sex } \\
\hline $\mathrm{F}$ & $108(65)$ & $82(64)$ & $108(65)$ \\
\hline M & $57(35)$ & $46(36)$ & $59(35)$ \\
\hline Employed or a student & $96(58)$ & $73(57)$ & $125(75)$ \\
\hline History of self-reported arthritis & $37(22)$ & $30(23)$ & $28(17)$ \\
\hline Annual household income $<$ US $\$ 50,000$ & - & $82(64)$ & $121(72)$ \\
\hline Joint pain day of interview & $59(36)$ & $34(27)$ & $14(8)$ \\
\hline Joint pain within month of interview & $87(53)$ & $51(40)$ & $26(16)$ \\
\hline \multicolumn{4}{|l|}{ Difficulty performing daily activities } \\
\hline Walking & - & $36(28)$ & $20(12)$ \\
\hline Climbing stairs & - & $40(31)$ & $20(12)$ \\
\hline Lifting heavy objects & - & $27(21)$ & $16(10)$ \\
\hline Getting in and out of cars & - & $27(21)$ & $10(6)$ \\
\hline Opening jars & - & $33(26)$ & $13(8)$ \\
\hline Sleeping & $27(31)$ & $19(37)$ & $8(29)$ \\
\hline Health somewhat/much worse after $1 \mathrm{y}$ & - & $28(22)$ & $16(10)$ \\
\hline $\begin{array}{l}\text { Subsample of participants reporting joint pain } \\
\text { within mo of interview }\end{array}$ & $\mathrm{N}=87$ & $N=51$ & $\mathrm{~N}=26$ \\
\hline Persistent arthralgia & $72(44)$ & $42(33)$ & $20(12)$ \\
\hline \multicolumn{4}{|l|}{ Joint pain frequency } \\
\hline Daily & $42(48)$ & $28(55)$ & $13(50)$ \\
\hline $2-3$ times/wk & $17(20)$ & $8(16)$ & $5(19)$ \\
\hline 1 time/wk & $13(15)$ & $6(12)$ & $2(8)$ \\
\hline$<1$ time/wk & $12(14)$ & $9(18)$ & $6(23)$ \\
\hline Not known & $3(3)$ & 0 & 0 \\
\hline Symmetrical joint pain & $27(31)$ & $14(27)$ & $7(27)$ \\
\hline \multicolumn{4}{|l|}{ Joint pain time of day } \\
\hline Morning & $16(18)$ & $12(24)$ & $2(8)$ \\
\hline Day & $10(11)$ & $5(10)$ & $1(4)$ \\
\hline Night & $11(13)$ & $6(12)$ & $5(19)$ \\
\hline Morning and night & $5(6)$ & $2(4)$ & $1(4)$ \\
\hline Present at all times or activity dependent & $43(49)$ & $23(45)$ & $15(58)$ \\
\hline Not known & $2(2)$ & $3(6)$ & $2(8)$ \\
\hline \multicolumn{4}{|l|}{ Worst time of day for joint pain } \\
\hline Morning & $29(33)$ & $21(41)$ & $3(12)$ \\
\hline Day & $9(10)$ & $7(14)$ & $1(4)$ \\
\hline Night & $20(23)$ & $8(16)$ & $8(31)$ \\
\hline Morning and night & $3(3)$ & $3(6)$ & 0 \\
\hline Present at all times or activity dependent & $23(26)$ & $8(16)$ & $12(46)$ \\
\hline Not known & $3(3)$ & $4(8)$ & $2(8)$ \\
\hline
\end{tabular}

Our comparative study had limitations, which may have influenced our findings. First, due to missing or incorrect contact information (online Technical Appendix Table 2), the study sample represents only $36 \%$ of eligible confirmed CHIKV case-patients and thus might not be representative of all USVI residents with CHIKV disease. Second, controls were younger than case-patients and were interviewed only once. Thus, we may have overestimated persistent arthralgia among case-patients due to progression of osteoarthritis associated with increased age and may have underestimated persistent arthralgia among controls. However, a BRFSS (Behavioral Risk Factor Surveillance System) survey indicated that $15 \%$ (95\% CI $14 \%-17 \%)$ of adult USVI residents reported having arthritis (15), a percentage consistent with our estimated persistent arthralgia prevalence among controls (17\%). Third, we did not test all controls for CHIKV IgG; thus, some controls with asymptomatic CHIKV infection may have been included in the analysis. However, prevalence differences were similar when we included controls who were asymptomatic but IgG-positive $(\mathrm{n}=12)$. Last, most case-patients knew their diagnosis, which may have influenced their reporting of persistence arthralgia, and case-patients with persistent arthralgia may have been more inclined to participate in the interviews. As a result of these limitations, we may have overestimated the association between persistent arthralgia and CHIKV disease up to 1 year after illness onset.

Our results emphasize that, in the USVI, CHIKV illness was associated with persistent arthralgia and difficulty with daily activities 1 year after disease onset. These 
findings highlight the need for therapeutic and vaccine research to manage and prevent acute illness and longterm sequelae associated with CHIKV infection. The results also underscore the need for studies to identify risk factors for long-term sequelae of CHIKV illness, to estimate the burden of persistent arthralgia after acute illness, and to understand the effect of persistent arthralgia on quality of life.

\section{Acknowledgments}

Assistance with data collection was provided by Michael Johansson, Christina Sancken, Zachary Heth and Elyse Phillips. Diagnostic expertise and assistance was generously provided by the Centers for Disease Control and Prevention.

This work was supported by the National Institutes of Health National Institute of Allergy and Infectious Disease (R37AI032042), and National Institute of General Medical Sciences (U54 GM111274) and by the US Virgin Islands Department of Health.

Dr. Feldstein is a postdoctoral research fellow at Fred Hutchinson Cancer Research Center. Her research focuses on the epidemiology of emerging and neglected tropical diseases.

\section{References}

1. Pan American Health Organization, World Health Organization. Chikungunya: statistics data. Geographic distribution, 2016 [cited 2016 Sep 9]. http://www.paho.org/hq/index.php?option=com_topic s\&view=readall $\&$ cid $=5927 \&$ Itemid $=40931 \&$ lang $=$ en

2. Centers for Disease Control and Prevention. Chikungunya virus. Geographic distribution [cited 2016 May 3]. http://www.cdc.gov/ chikungunya/geo/index.html

3. Staples JE, Breiman RF, Powers AM. Chikungunya fever: an epidemiological review of a re-emerging infectious disease. Clin Infect Dis. 2009;49:942-8.

4. Rodríguez-Morales AJ, Cardona-Ospina JA, Fernanda UrbanoGarzón S, Sebastian Hurtado-Zapata J. Prevalence of postchikungunya infection chronic inflammatory arthritis: a systematic review and meta-analysis. Arthritis Care Res (Hoboken). 2016;68:1849-58.

5. Javelle E, Ribera A, Degasne I, Gaüzère B-A, Marimoutou C, Simon F. Specific management of post-chikungunya rheumatic disorders: a retrospective study of 159 cases in Reunion Island from 2006-2012. PLoS Negl Trop Dis. 2015;9:e0003603.

6. Schilte C, Staikowsky F, Couderc T, Madec Y, Carpentier F, Kassab S, et al. Chikungunya virus-associated long-term arthralgia: a 36-month prospective longitudinal study. PLoS Negl Trop Dis. 2013;7:e2137.

7. Mohd Zim MA, Sam I-C, Omar SFS, Chan YF, AbuBakar S, Kamarulzaman A. Chikungunya infection in Malaysia: comparison with dengue infection in adults and predictors of persistent arthralgia. J Clin Virol. 2013;56:141-5.

8. Sissoko D, Malvy D, Ezzedine K, Renault P, Moscetti F, Ledrans M, et al. Post-epidemic Chikungunya disease on Reunion Island: course of rheumatic manifestations and associated factors over a 15-month period. PLoS Negl Trop Dis. 2009;3:e389.

9. Rodriguez-Morales AJ, Gil-Restrepo AF, Ramírez-Jaramillo V, Montoya-Arias CP, Acevedo-Mendoza WF, Bedoya-Arias JE, et al. Post-chikungunya chronic inflammatory rheumatism: results from a retrospective follow-up study of 283 adult and child cases in La Virginia, Risaralda, Colombia. F1000 Res. 2016;5:360.

10. Ellis E. Chikungunya surveillance weekly report. St. Croix (US Virgin Islands): US Virgin Islands Department of Health; 2015.

11. Feldstein LR, Ellis EM, Rowhani-Rahbar A, Halloran ME, Ellis BR. The first reported outbreak of chikungunya in the US Virgin Islands, 2014-2015. Am J Trop Med Hyg. 2016;95:885-9.

12. Pialoux G, Gaüzère B-A, Jauréguiberry S, Strobel M. Chikungunya, an epidemic arbovirus. Lancet Infect Dis. 2007;7:319-27.

13. Moro ML, Grilli E, Corvetta A, Silvi G, Angelini R, Mascella F, et al.; Study Group "Infezioni da Chikungunya in Emilia-Romagna". Long-term chikungunya infection clinical manifestations after an outbreak in Italy: a prognostic cohort study. J Infect. 2012;65:165-72.

14. Soumahoro M-K, Gérardin P, Boëlle P-Y, Perrau J, Fianu A, Pouchot J, et al. Impact of chikungunya virus infection on health status and quality of life: a retrospective cohort study. PLoS One. 2009; 4:e7800.

15. Centers for Disease Control and Prevention. BRFSS prevalence and trends data, 2010 [cited 2015 Jul 22]. https://www.cdc.gov/ brfss/brfssprevalence/index.html

Address for correspondence: Leora R. Feldstein, Fred Hutchinson Cancer Research Center, 1100 Fairview Ave N, Seattle, WA 98109, USA; email: lrfeldst@uw.edu 